\title{
For flux's sake: General considerations for energy-flux calculations in ecological communities
}

\author{
Malte Jochum ${ }^{1}$, Andrew Barnes ${ }^{2}$, Ulrich Brose ${ }^{1}$, Benoit Gauzens ${ }^{1}$, Marie Sünnemann ${ }^{1}$, \\ Angelos Amyntas ${ }^{1}$, and Nico Eisenhauer ${ }^{1}$ \\ ${ }^{1}$ German Centre for Integrative Biodiversity Research (iDiv) Halle-Jena-Leipzig \\ ${ }^{2}$ University of Waikato
}

February 23, 2021

\begin{abstract}
Global change alters ecological communities with consequences for ecosystem processes. Such processes and functions are a central aspect of ecological research and vital to understanding and mitigating the consequences of global change, but also those of other drivers of change in organism communities. In this context, the concept of energy flux through trophic networks integrates food-web theory and biodiversity-ecosystem functioning theory and connects biodiversity to multitrophic ecosystem functioning. As such, the energy flux approach is a strikingly effective tool to answer central questions in ecology and global-change research. This might seem straight forward, given that the theoretical background and software to efficiently calculate energy flux are readily available. However, the implementation of such calculations is not always straight forward, especially for those who are new to the topic and not familiar with concepts central to this line of research, such as food-web theory or metabolic theory. To facilitate wider use of energy flux in ecological research, we thus provide a guide to adopting energy-flux calculations for people new to the method, struggling with its implementation, or simply looking for background reading, important resources, and standard solutions to the problems everyone faces when starting to quantify energy fluxes for their community data. First, we introduce energy flux and its use in community and ecosystem ecology. Then, we provide a comprehensive explanation of the single steps towards calculating energy flux for community data. Finally, we discuss remaining challenges and exciting research frontiers for future energy-flux research.
\end{abstract}

\section{Hosted file}

Jochum_EcolEvol_2021_manuscript.pdf available at https://authorea.com/users/397544/ articles/510393-for-flux-s-sake-general-considerations-for-energy-flux-calculationsin-ecological-communities 


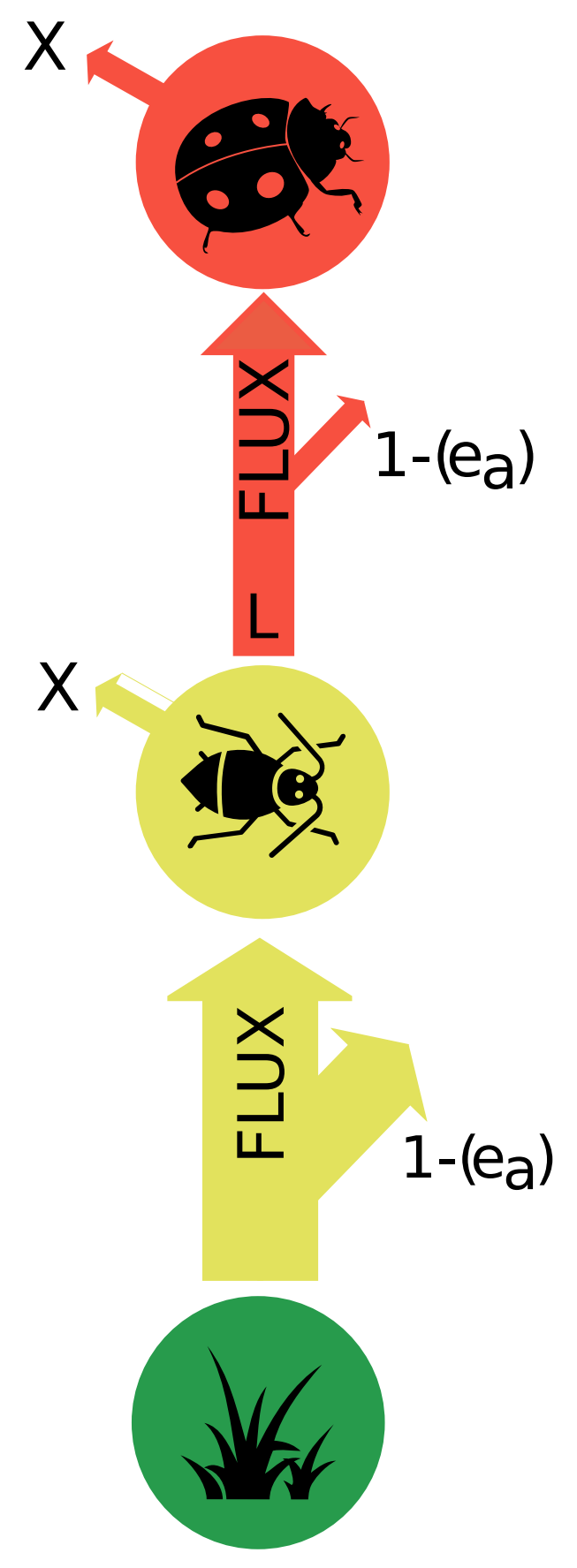



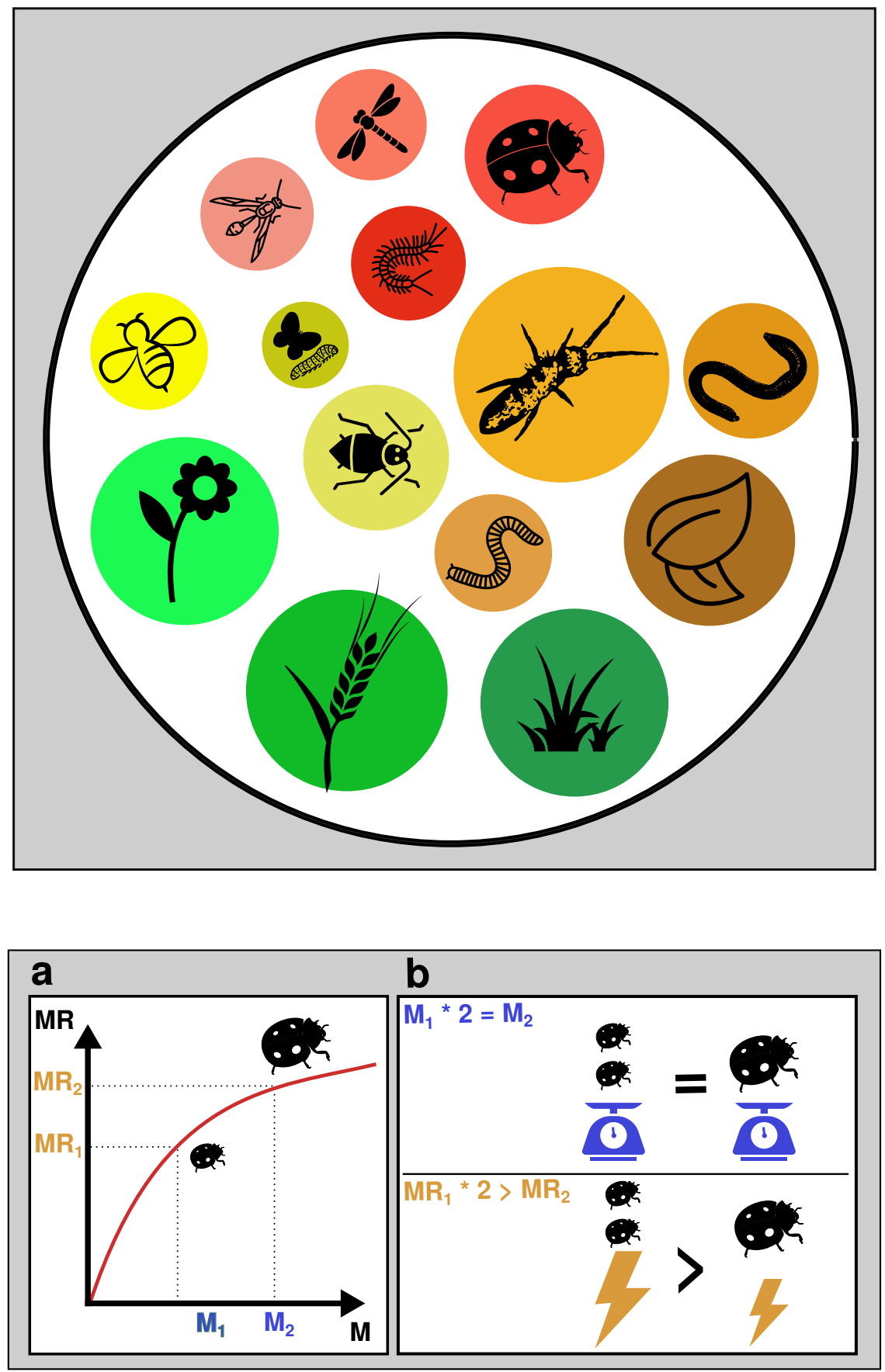

\section{Hosted file}

Jochum_EcolEvol_2021_Fig4.pdf available at https://authorea.com/users/397544/articles/510393for-flux-s-sake-general-considerations-for-energy-flux-calculations-in-ecologicalcommunities

\section{Hosted file}

Jochum_EcolEvol_2021_Fig5.pdf available at https://authorea.com/users/397544/articles/510393- 
for-flux-s-sake-general-considerations-for-energy-flux-calculations-in-ecologicalcommunities

\section{Hosted file}

Jochum_EcolEvol_2021_Fig6.pdf available at https://authorea.com/users/397544/articles/510393for-flux-s-sake-general-considerations-for-energy-flux-calculations-in-ecologicalcommunities

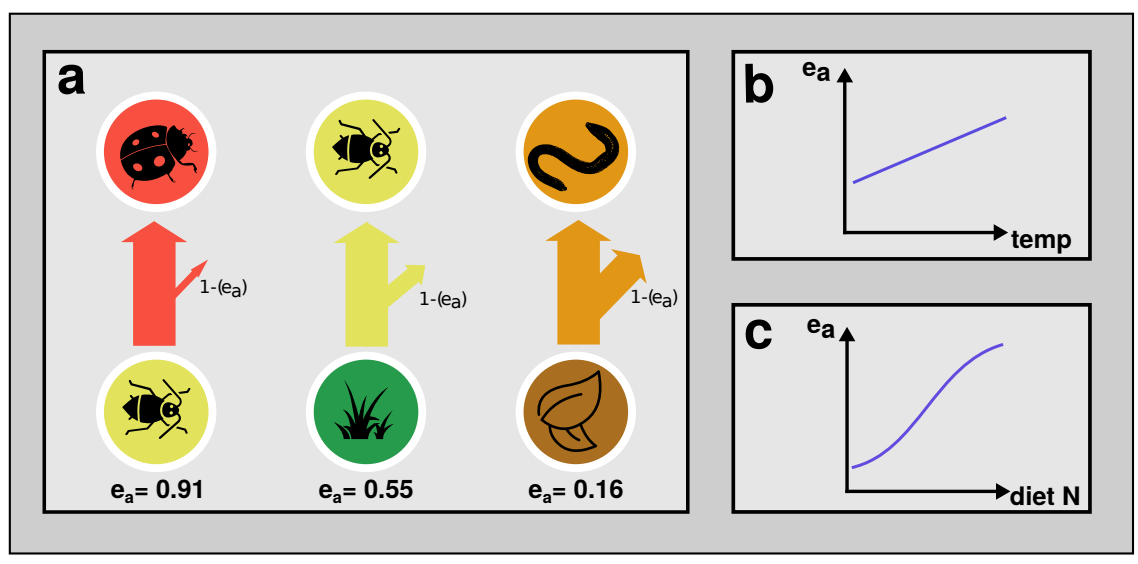

